\title{
Laser-induced fluorescence determination of temperatures in low pressure flames
}

\author{
Karen J. Rensberger, Jay B. Jeffries, Richard A. Copeland, Katharina Kohse-Höinghaus, Michael L. \\ Wise, and David R. Crosley
}

\begin{abstract}
Spatially resolved temperatures in a variety of low pressure flames of hydrogen and hydrocarbons burning with oxygen and nitrous oxide are determined from $\mathrm{OH}, \mathrm{NH}, \mathrm{CH}$, and $\mathrm{CN}$ laser-induced fluorescence rotational excitation spectra. Systematic errors arising from spectral bias, time delay, and temporal sampling gate of the fluorescence detector are considered. In addition, we evaluate the errors arising from the influences of the optical depth and the rotational level dependence of the fluorescence quantum yield for each radical. These systematic errors cannot be determined through goodness-of-fit criteria and they are much larger than the statistical precision of the measurement. The severity of these problems is different for each radical; careful attention to the experimental design details for each species is necessary to obtain accurate LIF temperature measurements.
\end{abstract}

\section{Introduction}

Laser-induced fluorescence (LIF) is an ideal diagnostic technique for the measurement of the concentrations of a variety of small free radical molecules which are important reaction intermediates in combustion chemistry. ${ }^{1}$ Diatomic hydride radicals such as $\mathrm{OH}, \mathrm{NH}$, and $\mathrm{CH}$, with their easily accessible excited electronic states, are readily observed by LIF in flame experiments. Although the $\mathrm{OH}$ radical has been the subject of the largest number of studies, simultaneous measurements of other species are needed to answer detailed questions about the flame chemistry. For example, the $\mathrm{NH}$ radical, unlike $\mathrm{OH}$, is present only in the reaction zone and is an important intermediate in the production of $\mathrm{NO}_{x}$ in flames containing either fuel nitrogen or oxidizers such as $\mathrm{NO}_{2}$ or $\mathrm{N}_{2} \mathrm{O}$. Prompt NO production is initiated by the reaction of $\mathrm{CH}$ with $\mathrm{N}_{2}$. In addition, $\mathrm{CH}$ emission and fluorescence are often used for diagnostics of the reaction zone of hydrocarbon flames. Besides the hydride radicals, the $\mathrm{CN}$ radical is another important intermediate species in $\mathrm{NO}_{x}$ production.

The spatial variation of the concentration of diatomic radicals in stable laminar flames can be predicted by computer model calculations and measured by LIF. ${ }^{2}$ A comparison of the predicted and measured variations of radical concentrations with position in the

The authors are with SRI International, 333 Ravenswood Avenue, Menlo Park, California 94025.

Received 9 November 1988.

0003-6935/89/173556-11\$02.00/0.

(C) 1989 Optical Society of America. flame provides a sensitive test of the chemical mechanism used in the model. Quantitative comparisons, whether on an absolute or relative basis, require knowledge of the gas temperature with precise spatial correlation to the LIF concentration measurement. There are two reasons for this. First and most important, the predictions of the model calculation at each point in the flame can be markedly different for temperature changes of 100-200 K because of the nonlinear effects of temperature upon a chemical reaction sequence. Second, the temperature is needed to relate number density in a particular rotational and vibrational level, as measured by the LIF intensity, to the total mole fraction of the radical species.

There are many methods to measure the gas temperature in flames, including both intrusive probe measurements and nonintrusive light scattering techniques. ${ }^{3}$ Included among the laser-based nonperturbative techniques are LIF, coherent and spontaneous Raman scattering, and Rayleigh scattering. ${ }^{4}$ Laserinduced fluorescence provides an excellent way to measure both the concentrations of the reactive intermediate radicals and spatially correlated temperatures. In this work, we discuss the use of LIF rotational excitation spectra for temperature measurement.

To obtain a rotational temperature, the radical is excited from several different rotational levels in the ground electronic state to an excited electronic state, from which it radiates. The fluorescence signal intensity for each individual transition is a measure of the population in that particular rotational level of the ground electronic state. In turn, the population distribution in the rotational levels is governed by the temperature. From the measured intensities and 
knowledge of the rotational line strengths $\left(B_{i}\right)$, the population in each level $N_{i}$ is determined. The temperature can be obtained from the slope of a Boltzmann plot of $\ln \left(N_{i} / g_{i}\right)$ versus $E_{i}$, where $g_{i}$ and $E_{i}$ are the degeneracy and energy, respectively, of the ground state level $i$. Alternatively, a portion of a rotational excitation spectrum may be directly fit to determine a temperature. This technique has the obvious advantage in being able to use complex, overlapped spectra.

In this paper, we describe in detail experiments on $\mathrm{OH}$ performed in stable, laminar, low pressure flames of $\mathrm{H}_{2}$ burning in $\mathrm{O}_{2}$ and $\mathrm{N}_{2} \mathrm{O}$. These experiments investigate the influence of rotational-level-dependent quantum yield and detector wavelength response function (spectral bias) on the apparent gas temperature. For $\mathrm{OH}$ we also investigate the effects of optical depth, manifest as significant absorption of the laser beam and fluorescence across the burner. Low pressure flames offer special advantages for these purposes. First, the temperature gradients are gradual compared with the laser spatial cross section. Second, collisional quenching is reduced so that the excited state lifetime is significantly longer than the duration of the laser pulse and the direct time decay of the fluorescence can be used to study collisional effects. We find that the detector spectral bias, the optical depth, and the rotational-level-dependent quantum yield can produce significant systematic errors in addition to the statistical precision of the LIF temperature determination. We will demonstrate for $\mathrm{OH}$ that even if the influence of these parameters is neglected, the rotational spectra (or Boltzmann plots) are still satisfactorily fit to a temperature. This temperature can deviate by as much as several hundred degrees from the true value, i.e., that correctly determined by properly taking all these effects into account. The magnitude of these systematic errors cannot be determined by statistical measures of precision but often must be evaluated experimentally.

Measurements on $\mathrm{NH}, \mathrm{CH}$, and $\mathrm{CN}$ in hydrogen or propane flames burning with oxygen or nitrous oxide allow comparisons of the temperatures obtained in the same flame with different radicals. The optical depth problem is not observed for these radicals, but the detector spectral bias and the rotational level dependence of the quantum yield is still a concern.

The section below on the experimental technique includes a brief description of the low pressure flame apparatus and a discussion of the detection considerations for each of the radicals: $\mathrm{OH}, \mathrm{NH}, \mathrm{CH}$, and $\mathrm{CN}$. The influence of rotational energy transfer, the rotational dependence of the transition moment, and the optical depth of the LIF temperature are studied in detail for $\mathrm{OH}$. In the following section, temperature measurements on each of the radicals are then compared.

In addition to their direct applicability to low pressure flames, the present results provide guidance for temperature measurements at atmospheric pressure using LIF of radicals. Our use of a narrow (10-30-ns) detector gate placed at the signal peak minimizes the effects of rotational energy transfer and rotationallevel-dependent quantum yields seen when integrating the entire fluorescence decay over time. In contrast, at atmospheric pressure, detector temporal bandwidth $>1 \mathrm{GHz}$ and picosecond laser pulses are necessary to time resolve the fluorescence. The effects on the measurement due to rotational-level-dependent quantum yields must be carefully taken into account when applying this work to higher pressure flames.

\section{Experimental Technique}

\section{A. Experimental Apparatus}

The low pressure burner apparatus is discussed in detail elsewhere, ${ }^{5}$ and only the aspects important to temperature measurements will be discussed here. Flames of hydrogen or propane are burned with either oxygen or nitrous oxide. These flames are supported on a 6-cm diameter porous plug McKenna burner which resides in an evacuated chamber and can be scanned vertically with an accuracy and reproducibility of $0.1 \mathrm{~mm}$. For most experiments, the pressure ranges between 6 and 15 Torr. The laser beam usually traverses the burner horizontally at the center, resulting in a detection path length through the flame of 3 $\mathrm{cm}$. For the $\mathrm{OH}$ measurements, because absorption of the beam is substantial ( $9 \%$ for the strong lines in the $R$ branch) the burner is positioned with the laser beam closer to the burner edge, yielding a detection path length of $1.25 \mathrm{~cm}$. The collimated laser beam is apertured with a measured beam diameter of $\sim 0.5 \mathrm{~mm}$, which corresponds to a temperature spread of about $100 \mathrm{~K}$ in the region of the largest temperature gradient in the hottest flames and proportionately less in the cooler flames.

Light from a pulsed $\mathrm{XeCl}$ excimer-pumped dye laser with a pulse length of $\sim 12 \mathrm{~ns}$ excites the radicals from the $v^{\prime \prime}=0$ level in the ground state to $v^{\prime}=0$ in the excited state. Table I lists the specific band system for each radical and the laser dye used. In all cases, the laser intensity is attenuated to insure that the excitation transition is not saturated and the LIF signal is linear with laser power.

The LIF is collected with $f / 3$ optics and focused at $f /$ 4 into a $0.3-\mathrm{m}$ monochromator used as an adjustable bandpass optical filter. The light is detected with a 1P28 photomultiplier, amplified, and captured with a boxcar integrator. Typically, between 10 and 100 laser shots at each wavelength are summed to obtain the signal. The time delay between the excitation laser and the detection gate as well as the time width of that gate are discussed in detail below. For reasons discussed below, the detector must have a constant response over the entire wavelength region of the vibrational band detected. A $0.3-\mathrm{m}$ monochromator with 0.5 -mm entrance and 4-mm output slit provides a trapezoidal shaped spectral response function with a 20 $\mathrm{nm}$ bandpass at the top of the trapezoid and a $23-\mathrm{nm}$ bandpass at the base. 


\section{B. Spectral Fitting}

To obtain a rotational temperature, the wavelength of the excitation laser is scanned to excite the radical from several different rotational levels and/or fine structure levels of the ground electronic state. The signal intensity $I_{i}$ obtained when exciting from level $i$ in the ground state to level $f$ in the excited state and collecting all the fluorescence is

$$
I_{i}=G \Phi_{i} B_{f i} N_{i},
$$

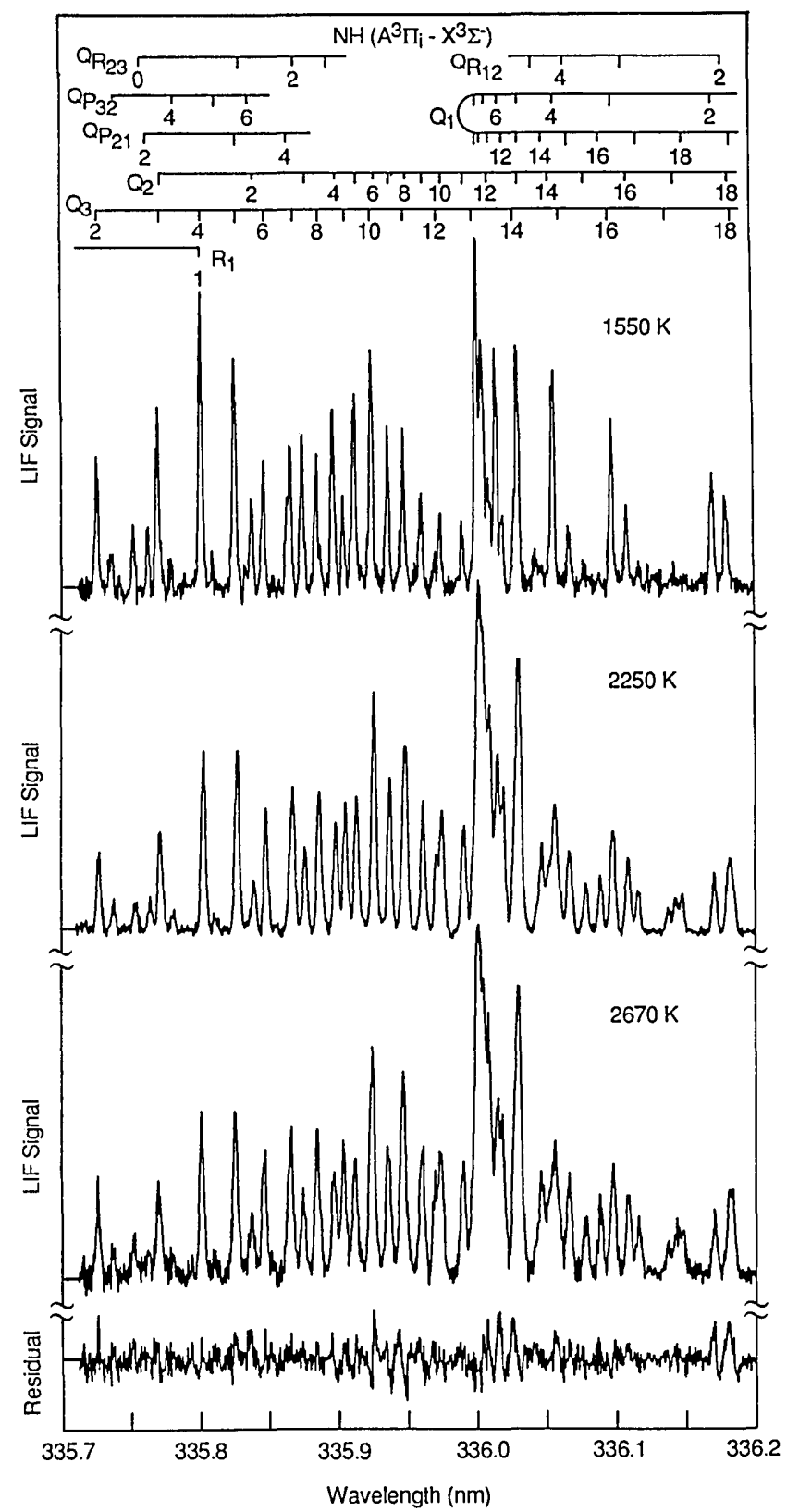

Fig. 1. Experimental LIF rotational excitation spectra of the $Q$ head region of the $\mathrm{NH}\left(A^{3} \Pi_{i}-X^{3} \Sigma^{-}\right)$transition for a 13.8-Torr, $\phi=$ 1.04, $\mathrm{C}_{2} \mathrm{H}_{2} / \mathrm{N}_{2} \mathrm{O}$ flame. The spectra are obtained (top to bottom) at $1.1,4.0$, and $7.3 \mathrm{~mm}$ above the burner and are fit to temperatures of 1050,2250 , and $2670 \mathrm{~K}$, respectively. The bottom trace is the residual of the fit at $2670 \mathrm{~K}$. The transitions are labeled by the ground state total angular momentum quantum number $J$. where $G$ is a constant related to the light collection efficiency, $B_{f i}$ is the excitation line strength for the respective rotational line, and $N_{i}$ is the population in level $i$. The fluorescence quantum yield $\Phi_{f}$ is $A_{f} /\left(A_{f}+\right.$ $Q+k_{\text {pre }}$ ), where $A_{f}$ is the Einstein $A$ coefficient, $Q$ is the total collisional quenching rate, and $k_{\text {pre }}$ is the predissociation rate. The fluorescence quantum yield depends on the rotational transition and collision environment; in low pressure flames, it may be quite high, around 0.2 or so, while at atmospheric pressure it is greatly reduced by collisional quenching. A recent approach applicable to $\mathrm{O}_{2}$ and $\mathrm{OH}$ attempts to avoid the quenching problem by exciting transitions which are strongly predissociated. ${ }^{6-8}$ In this case, the quantum yield depends only on the predissociation rate but at a significant cost in signal levels. For the temperature measurements described here, the quantum yields may be directly measured. From the LIF line intensities and knowledge of the rotational line strengths and fluorescence quantum yields, the relative $N_{i}$ can be determined. The population in each rotational level is proportional to $g_{i} \exp \left(-E_{i} / k T\right)$. The temperature can be obtained from the slope of a Boltzmann plot of $\ln \left(N_{i} / g_{i}\right)$ versus $E_{i}$.

Alternatively, a portion of the rotational excitation spectrum can be directly fit by a least-squares procedure to determine a temperature; here, the line positions, rotational line strengths, and energy levels are input data. There are only two free parameters in such a fit: the temperature and linewidth. Direct spectrum fitting to determine temperature is the accepted technique for CARS, ${ }^{9}$ and has been done elsewhere for LIF. ${ }^{10}$ The advantage of such direct fits is that individual intensities do not need to be extracted from overlapping transitions in the spectrum. For example, Fig. 1 shows the excitation spectrum in the $Q$ branch region of the $\mathrm{NH} A-X$ system which we use to obtain $\mathrm{NH}$ temperatures. Here we scan only $0.5 \mathrm{~nm}$ and excite more than 50 transitions with $N^{\prime \prime}$ between 1 and 20. At this laser resolution, this region is too congested to determine straightforwardly individual $N_{i}$ and obtain the temperature from Boltzmann plots. Table I contains the scan ranges and other pertinent data for $\mathrm{OH}, \mathrm{NH}, \mathrm{CH}$, and $\mathrm{CN}$.

The experimental spectrum is fit by comparing it to a synthesized spectrum and varying the fit parameters (temperature and Gaussian linewidth) to minimize the sum of the squares of the residuals. The line positions and line strengths of the transitions and the ground state energy levels are the necessary input to the fit. The remainder of this section describes how these are obtained and some details of the fitting procedure.

The line positions, as well as the spectroscopic labeling, for the $\mathrm{OH}(A-X)$ transitions are obtained from Dieke and Crosswhite ${ }^{11}$ and for $\mathrm{NH}(A-X)$ from Brazer, Ram, and Bernath. ${ }^{12}$ The line positions for $\mathrm{CH}(A-$ $X)$ and $\mathrm{CH}(B-X)$ are from Moore and Broida ${ }^{13}$; the labeling is as suggested in Ref. 14. The line positions for $\mathrm{CN}$ are calculated as described below from the molecular constants given by Colket. ${ }^{15}$ The calculated spectrum for the $\mathrm{CN}$ radical agrees to within $0.01-\AA$ 


\begin{tabular}{|c|c|c|c|c|c|}
\hline Radical & $\mathrm{OH}$ & $\mathrm{NH}$ & $\mathrm{CH}$ & $\mathrm{CH}$ & $\mathrm{CN}$ \\
\hline System & $\mathrm{A}^{2} \Sigma^{+}-\mathrm{X}^{2} \Pi_{\mathrm{i}}$ & $A^{3} \Pi_{i}-X^{3} \Sigma^{-}$ & $\mathrm{A}^{2} \Delta-\mathrm{X}^{2} \Pi$ & $\mathrm{B}^{2} \Sigma^{-}-\mathrm{X}^{2} \Pi$ & $\mathrm{B}^{2} \Sigma^{+}-\mathrm{X}^{2} \Sigma^{+}$ \\
\hline Band & $(0,0)$ & $(0,0)$ & $(0,0)$ & $(0,0)$ & $(0,0)$ \\
\hline Laser Dye & $\begin{array}{l}\text { Sulforhodamine B } \\
\text { (doubled) }\end{array}$ & PTP & Coumarin 120 & QUI & QUI \\
\hline Scan range ${ }^{a}$ & $306.71-307.06$ & $335.70-336.20$ & $429.76-430.48$ & $387.10-387.77$ & $387.37-387.78$ \\
\hline $\begin{array}{l}\text { Detector center } \\
\text { position }^{\mathrm{a}}\end{array}$ & 312 & 336 & 430 & 393 & 387 \\
\hline $\begin{array}{l}\text { Number of significant } \\
\text { lines }\end{array}$ & 15 & 60 & 21 & 19 & 24 \\
\hline Range of $\mathrm{N}^{\prime \prime}$ & $2-15$ & $1-20$ & $1-2,11-15$ & $2-11$ & $1-4,52-58$ \\
\hline $\begin{array}{l}\text { Thermal bandwidth } \\
(2500 \mathrm{~K})\end{array}$ & 20 & 18 & 25 & 20 & 8 \\
\hline $\begin{array}{l}\text { Bandwidth of levels } \\
\text { excited }^{a, b}\end{array}$ & 13 & 14 & 16 & 11 & 8 \\
\hline Significant transitions & $\begin{array}{l}\mathrm{R}_{1}(2-4) \\
\mathrm{R}_{1}(14,15) \\
\mathrm{R}_{2}(6-13) \\
\mathrm{R}_{\mathrm{Q}_{21}}(2-4)\end{array}$ & $\begin{array}{l}\mathrm{Q}_{1}(2-20) \\
\mathrm{Q}_{2}(2-20) \\
\mathrm{Q}_{3}(1-19)\end{array}$ & $\begin{array}{l}\mathrm{R}_{1}(1,2) \\
\mathrm{R}_{2}(1) \\
\mathrm{Q}_{1}(11-15) \\
\mathrm{Q}_{2}(11-15)\end{array}$ & $\begin{array}{l}\mathrm{R}_{1}(3-11) \\
\mathrm{R}_{2}(2-11)\end{array}$ & $\begin{array}{l}\mathrm{R}_{1}(0,1) \\
\mathrm{R}_{2}(1) \\
\mathrm{P}_{1}(1-4,52-58) \\
\mathrm{P}_{2}(1-4,52-58)\end{array}$ \\
\hline
\end{tabular}

aUnit of wavelength is $\mathrm{nm}$.

bBandwidth needed to detect all fluorescence originating from excited levels, assuming no rotational energy transfer occurs.

with published wavelengths for $N^{\prime \prime}$ from 1 to $49 .{ }^{16}$ No tabulated line positions were found for $N^{\prime \prime}$ from 52 to 58 , so the calculated line positions for $N^{\prime \prime}$ from 52 to 58 are adjusted to match the experimental spectrum as described next.

The experimental spectrum as it is obtained is not linear in wavelength. The laser stepping motor drive shows an oscillatory behavior that is evident when the experimental wavelengths of the transitions are compared to known line positions. For the short scan regions needed here, the nonlinearity appears to be a slow curve and can be fit to a three-term polynomial, which is used to adjust the synthesized line positions to match the experimental line positions. Each scan region is calibrated separately, as the nonlinearity varies from region to region.

The linewidth determined by the spectral fitting procedure is a convolution of the laser linewidth and the Doppler width of the transition. Our measured linewidth for the doubled laser output at $310 \mathrm{~nm}$ is 0.2 $\mathrm{cm}^{-1}$ and is not sufficiently narrow to accurately determine the temperature just from the Doppler width of the transitions. The linewidths from the $\mathrm{CH}$ and $\mathrm{CN}$ spectra are generally twice as wide, due to a larger laser linewidth, than those for the $\mathrm{OH}$ and $\mathrm{NH}$ spectra. The fit to determine the temperature is not highly dependent on the value for the linewidth, as the sum of squares of the residuals from the fit changes less than $1 \%$ for a change in the linewidth of $0.002 \AA$.

The rotational line strengths for each radical are calculated after the approach developed by Zare et al. ${ }^{17}$ A computer program calculates the position and line strength of rotational lines of an electric dipole allowed transition from molecular constants using a model Hamiltonian described by Zare et al. Some of the molecular constants needed are the term origin, the rotational constants, the spin-orbit splitting constants, and the spin-rotation splitting constants. A note of caution is deserved here. Depending on which set of molecular constants is used, large differences on the order of 1 to $2 \AA$ between the calculated and tabulated line positions are seen, especially for $\mathrm{CH}$ and $\mathrm{NH}$. The differences appear to be the greatest when there is significant $\lambda$-doubling in a $\Pi$ state. It is preferable to use a set of constants for both the excited and ground states obtained using the same Hamiltonian used to calculate the line positions and line strengths. Since tabulated line positions are readily available for all the radicals but $\mathrm{CN}$, we use these in the temperature fitting. The rotational line strengths calculated are not as sensitive to the molecular constants as the line positions and are used in the spectral fitting program. The 
constants for $\mathrm{NH}$ are given in the same reference as the line positions. Those for $\mathrm{CH}$ are given in Ref. 18-20. The constants for $\mathrm{OH}$ are obtained from fitting the tabulated line positions in Dieke and Crosswhite with the Zare et al. method.

In calculating the rotational line strengths in the program it was assumed that the electronic transition moment is independent of the internuclear separation. This is a poor assumption for $\mathrm{OH} .{ }^{21}$ The variation in the electronic transition moment with internuclear distance seen for $\mathrm{OH}$ manifests itself in a rotational level dependence of the electronic transition moment. ${ }^{22}$ Neglecting this, the magnitude of the error in the temperatures for spectra fit to rotational line strengths can be estimated from

$$
T_{\text {corrected }}=T_{\text {observed }}\left(1-\gamma T_{\text {observed }}\right)^{-1} \text {. }
$$

The parameter $\gamma$ is $3.24 \times 10^{-5}$ for $\mathrm{OH}$, calculated from spectroscopic considerations including the internucle-

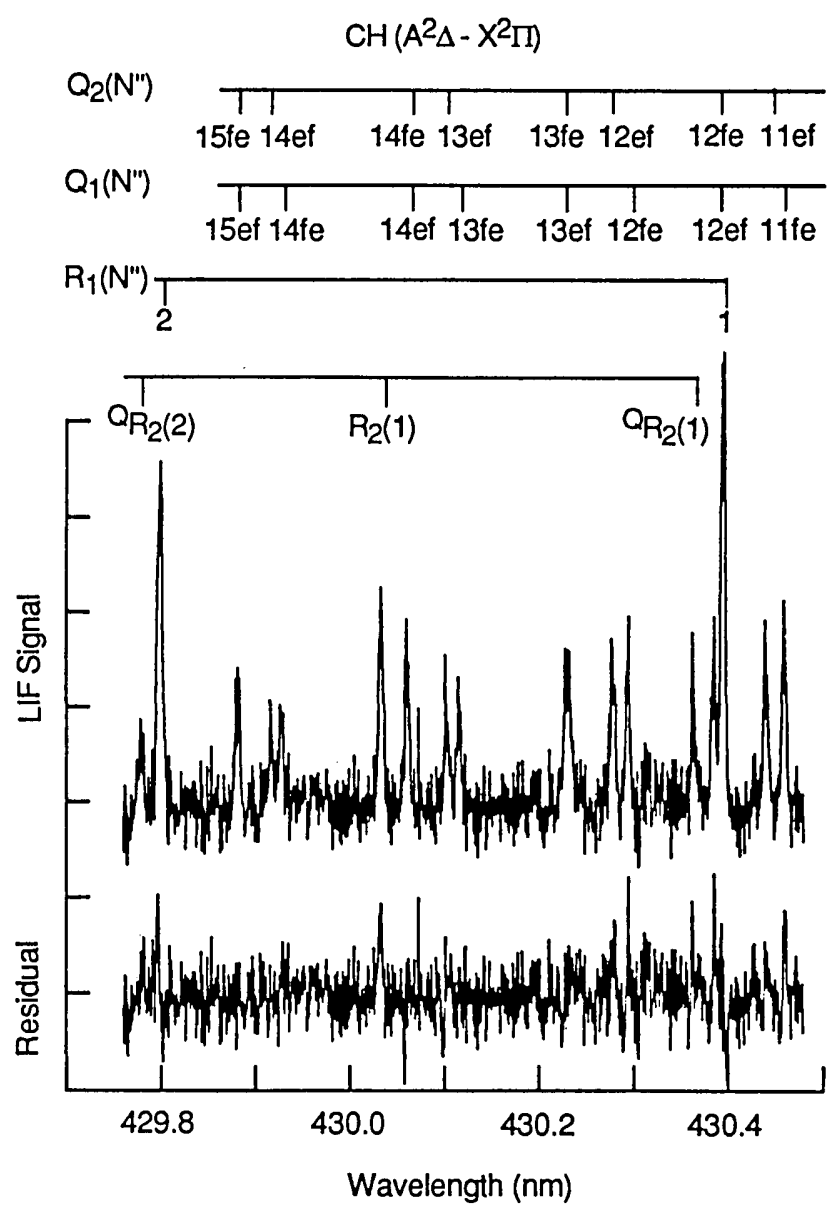

Fig. 2. Experimental LIF spectrum of part of the $\mathrm{CH}\left(A^{2} \Delta-X^{2} \Pi\right)$ transition in a 6.8-Torr, $\phi=1, \mathrm{C}_{3} \mathrm{H}_{8} / \mathrm{O}_{2}$ flame. A fit to this spectrum yields a temperature of $1900 \mathrm{~K}$. The residual to the fit is shown in the lower trace. The rotational transitions are relabeled to correspond to the notation suggested by Ref. 14 .

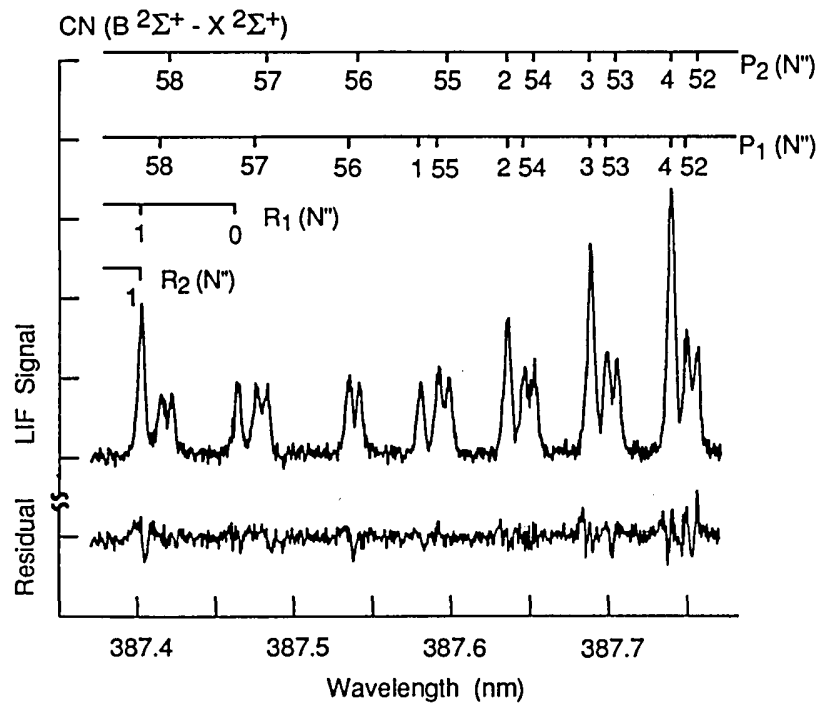

Fig. 3. Experimental LIF spectrum of part of the $\mathrm{CN}\left(B^{2} \Sigma^{+}-X^{2} \Sigma^{+}\right)$ transition in a 15 -Torr, $\phi=1.33, \mathrm{C}_{3} \mathrm{H}_{8} / \mathrm{N}_{2} \mathrm{O}$ flame. A fit to this spectrum yields a temperature of $2575 \mathrm{~K}$. The residual to the fit is shown in the lower trace.

ar distance dependence of the transition moment. ${ }^{21}$ For $\mathrm{OH}$, we fit some of the rotational excitation spectra with line strengths, neglecting the rotational variation of the electronic transition moment. A flame at 2300 $\mathrm{K}$ produces an apparent temperature low by $180 \mathrm{~K}$ and at $1200 \mathrm{~K}$ produces a result low by $35 \mathrm{~K}$, in excellent agreement with the prediction of Eq. (2). All of the $\mathrm{OH}$ temperatures discussed in this work are obtained by using the corrected line strengths. ${ }^{22}$ The $\mathrm{NH}$ and $\mathrm{CH}$ radicals have substantially less variation of the transition moment with rotational level: $\gamma=5.4 \times$ $10^{-6}$ for $\mathrm{NH}\left(A^{3} \Pi_{i}\right), \gamma=3.2 \times 10^{-6}$ for $\mathrm{CH}\left(A^{2} \Delta\right)$, and $\gamma$ $=5.2 \times 10^{-6}$ for $\mathrm{CH}\left(B^{2} \Sigma^{-}\right)$. The error thus produced for these radicals is estimated to be less than $30 \mathrm{~K}$ for the highest temperatures. This systematic error is less than the precision of the measurements discussed here. For nonhydride radicals, $\gamma$ is generally too small to influence temperature measurements.

A list of the ground state energy levels needed to calculate rotational populations at a given temperature is obtained from the computer program used to calculate rotational line strengths. Each rotational level is split to give $F_{1}$ and $F_{2}$ components for $\mathrm{OH}, \mathrm{CH}$, and $\mathrm{CN}$, and into three analogous components for $\mathrm{NH}$. For our purposes, for $\mathrm{NH}$ and $\mathrm{CN}$, the splitting is small and is ignored. The $\lambda$-doublet splitting for $\mathrm{OH}$ and $\mathrm{CH}$ is also small and is neglected.

The scan ranges listed in Table $\mathrm{I}$ cover a range of low and high rotational levels. For $\mathrm{OH}, \mathrm{NH}$, and $\mathrm{CH}(B-$ $X)$, the rotational levels cover a range through which temperatures from room temperature to $2500 \mathrm{~K}$ and higher can be measured. The $\mathrm{CH}(A-X)$ scan range that is listed covers low rotational levels and very high ones. It is best for flames above $1500 \mathrm{~K}$; a different range that covers intermediate rotational levels is necessary for cooler flames, such as for measurements on the $\mathrm{H}_{2} / \mathrm{O}_{2}$ flame seeded with $\mathrm{CH}_{4}$. The $\mathrm{CN}$ scan range 
is similar, in that a different set of rotational levels may be necessary to measure temperatures lower than 1900 K.

It is difficult to assess how noise-free a spectrum must be in order for it to yield a meaningful temperature. The $\mathrm{OH}$ and NH (Fig. 1) spectra are of much higher quality than the $\mathrm{CH}$ and $\mathrm{CN}$ spectra. Examples of spectra for $\mathrm{CH}(A-X)$ and $\mathrm{CN}$ are shown in Figs. 2 and 3 and for $\mathrm{CH}(B-X)$ in Ref. 23. The signal to noise ratio for the $\mathrm{CN}$ spectrum for the small peaks, which correspond to high rotational levels and are most sensitive to the temperature, is about 3 and becomes worse at lower temperatures. The $\mathrm{CH}$ spectra, in general, are of lower quality than those for $\mathrm{OH}$ and $\mathrm{NH}$, mainly due to a much smaller concentration of the $\mathrm{CH}$ radical in the flames.

\section{Detector Response Requirements}

To determine the bandpass necessary to detect the LIF without spectral bias requires a discussion of the spectroscopy and collisional energy transfer of the radical. The spectral bias problem has been discussed in detail for atmospheric pressure flames ${ }^{24}$ and is summarized here. In LIF, the laser light excites the radical to a particular rotational and vibrational level of the excited electronic state. The initially excited level can radiate, undergo energy transfer to other rotational or fine structure levels of the same electronic state which subsequently radiate, or be collisionally removed from the manifold of radiating levels to another electronic state. All radiation emitted in the detector spectral bandpass forms the LIF signal. Each level radiates with characteristic transitions $(P, Q, R)$ to the ground electronic state. The line strengths and selection rules governing these transitions vary with each molecule; however, the emission in each vibrational band occurs over a finite range of wavelengths. The large rotational constant of the hydride radicals extends the spread of wavelengths. For example, the calculated $(0,0)$ bands for the radicals $\mathrm{OH}(A-X)$, $\mathrm{NH}(A-X), \mathrm{CH}(A-X), \mathrm{CH}(B-X)$, and $\mathrm{CN}(B-X)$, at $2500 \mathrm{~K}$ are illustrated in Fig. 4. The spectra in this figure show that if the excited electronic state is rotationally equilibrated at $2500 \mathrm{~K}$, fluorescence from each radical will extend over a wide (15-25-nm) range; the width of the spectrum for each of the radicals is given in Table I.

In these experiments with flames between 5 and 15 Torr, we estimate the average time between rotational energy transfer collisions to be about $30 \mathrm{~ns}$. Thus, if we use a narrow detector (boxcar) gate of $10 \mathrm{~ns}$ during or promptly after the 15-ns laser pulse, the excited state population distribution of the radiating molecule will be dominated by the initial level. Significant additional population will be found in only those levels adjacent to it. For this case, the required bandpass is dictated by the range of rotational levels excited and the wavelength of their $P$-, $Q$-, and $R$-branch transitions. For the $\mathrm{OH}$ rotational levels excited here, $3 \leq$ $N^{\prime} \leq 16$, the required bandwidth to detect all the light

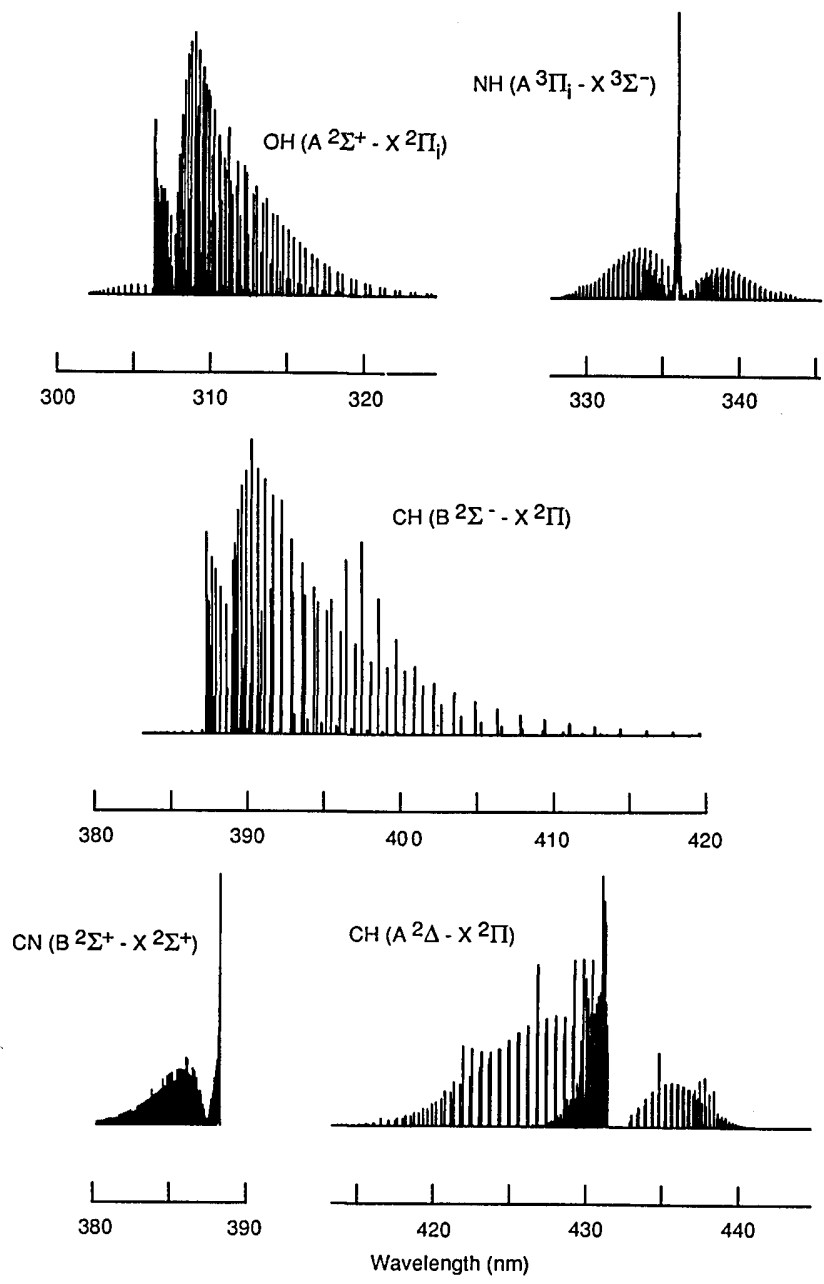

Fig. 4. Synthesized $\mathrm{OH}, \mathrm{NH}, \mathrm{CN}$, and $\mathrm{CH}$ emission spectra at 2500 K. At this temperature, the transitions extend over many nanometers. The $y$-axis scale is different for each band shown.

becomes $13 \mathrm{~nm}$. The requirements for the other radicals are listed in Table I.

Alternatively, if energy transfer collisions create a thermal population distribution in the excited electronic state before the fluorescence is detected, then this light will have the same spectral distribution for any initially excited level and can be detected with any broad or narrow bandpass spectral response. However, this case also requires a delay between the excitation laser pulse and the detector time gate to permit sufficient rotational relaxation. For the hydride radicals, collisional quenching is competitive with rotational energy transfer. ${ }^{24-28}$ Thus, the delay while waiting for thermalization of the excited state population also reduces the signal by at least a factor of 10 . Such a scheme was applied ${ }^{2}$ to low pressure flames where the fluorescence lifetime of the radical is long compared to the laser pulse length. In an atmospheric pressure flame, the collision rates become so fast that the fluorescence is quenched rapidly compared to the 12-ns laser pulse and thermalization is never achieved. ${ }^{24-26}$ Only the time integrated fluorescence, 
which has a rotational distribution far from thermal, can be easily detected.

To test the effects of spectral bias, we shift the 20$\mathrm{nm}$ bandpass detector to be centered at $320 \mathrm{~nm}$. This is about $8 \mathrm{~nm}$ to the red of the optimum for the $\mathrm{OH}$ detection. The detector will then collect the light from the $P$ - and $Q$-branch transitions with high rotational quantum number with greater efficiency than from those with lower $N$. Most of the $R$-branch ( $J<$ 19.5) and some of the $Q_{1}$ branch $(J<6)$ will not be detected. The rotational excitation spectrum listed in Table I is then scanned in the burnt gases of a 7.2-Torr, stoichiometric $\mathrm{H}_{2} / \mathrm{N}_{2} \mathrm{O}$ flame. Instead of the $2300 \mathrm{~K}$ temperature measured with the optical bandpass properly adjusted, the rotational excitation spectrum is fit by a temperature of $3770 \mathrm{~K}$ with a statistical precision of $\sim 150 \mathrm{~K}$. Note the goodness of fit shown in the Boltzmann plot in Fig. 5, even though the resulting temperature is clearly not possible in such a flame. The adiabatic flame temperature is $2600 \mathrm{~K}$. The spectral fit also does not show any obvious bias. The use of a narrow bandpass detector $(1.3 \mathrm{~nm})$, centered on the low $N$ region of the $Q$-branch bandhead, has been previously demonstrated ${ }^{24}$ in atmospheric flames to give precise temperatures as much as $800 \mathrm{~K}$ lower than those detected without spectral bias. For similar reasons, the use of a 10-nm bandwidth for the detection centered on the $Q$-branch fluorescence of the $\mathrm{CH} B-X$ rotational excitation spectrum in Table I results in a temperature $\sim 400 \mathrm{~K}$ too cold. Switching to the $20-\mathrm{nm}$ bandwidth solved this problem for the $\mathrm{CH} B-X$ system. These examples clearly show that statistical measures of precision do not provide warnings of possi-

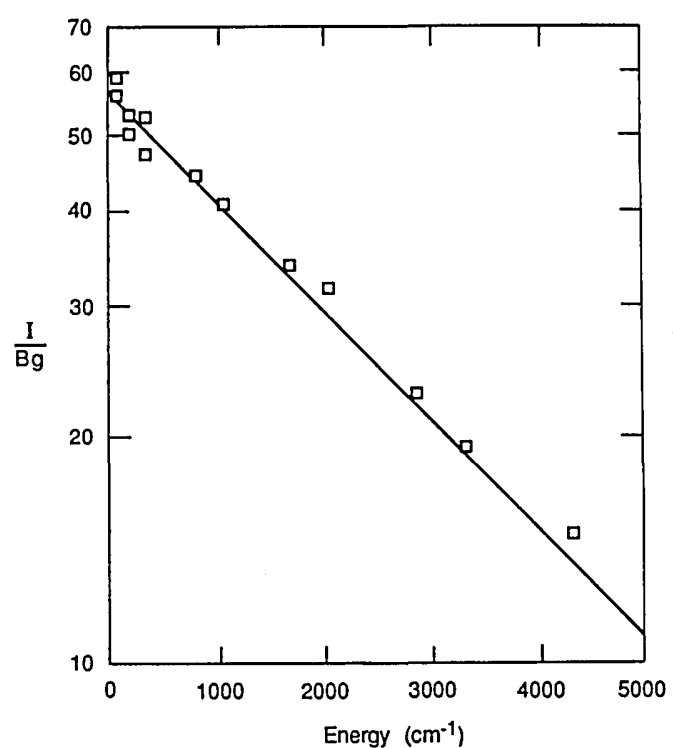

Fig. 5. Boltzmann plot of the $\mathrm{OH}\left(A^{2} \Sigma^{+}-X^{2} \Pi_{i}\right)$ normalized intensity divided by the line strength and degeneracy vs. rotational energy for a 7.2-Torr, $\phi=1, \mathrm{H}_{2} / \mathrm{N}_{2} \mathrm{O}$ flame, in which the spectral bandpass preferentially detects the high rotational levels. The line corresponds to a temperature of $3770 \mathrm{~K}$. The correct temperature of 2300 $\mathrm{K}$ is obtained by using the proper bandpass. ble systematic errors which can severely limit the accuracy of the measured temperature. Rather, the collisional energy transfer and spectroscopy for each radical must be considered.

\section{Laser-Detector Timing}

Changes in the fluorescence quantum yield with rotational level can affect the measured temperatures. There are three rotational-level-dependent terms in the quantum yield: the oscillator strength, noted above for the absorption transition, the collisional quenching rate, and the predissociation rate. The radiative lifetimes of $\mathrm{OH}, \mathrm{NH}$, and $\mathrm{CH}$ depend on rotational level, although this variation is the largest in OH. ${ }^{29}$ The higher rotational levels have a longer radiative lifetime. In addition, at room temperature, the collisional quenching rates of both $\mathrm{OH}$ and $\mathrm{NH}$ decrease with increasing rotation of the electronically excited radical. ${ }^{30}$ Consequently, moving the detector gate to longer delays will increase the relative amount of fluorescence from higher rotational levels and the apparent temperature will become higher. For $\mathrm{OH}$, we tested this in the burnt gases of a 7.2-Torr $\mathrm{H}_{2} / \mathrm{N}_{2} \mathrm{O}$ flame near $2300 \mathrm{~K}$; here the fluorescence lifetime is $\sim 100$ ns. Several boxcars recorded the rotational spectrum simultaneously, each with a 10-ns gate at different gate delays. The spectra obtained in this way are compared to one obtained from a prompt 10-ns gate. The systematic error $\Delta T$ increases smoothly from $80 \mathrm{~K}$ at $50-\mathrm{ns}$ delay to $240 \mathrm{~K}$ at $250-\mathrm{ns}$. When a wide (300-ns) gate is used to integrate all the fluorescence, the error is $+100 \mathrm{~K}$. All of the fits to the spectra have satisfactory statistical precision, again much smaller than this systematic deviation.

A rotational-level-dependent quantum yield for the LIF has been observed for $\mathrm{OH},{ }^{31} \mathrm{CH}, 5,32$ and $\mathrm{NH}^{32,33}$ in low pressure flames. However, for the flames studied here, the 10-ns detector gate is short compared to the fluorescence lifetime of all the radicals studied except CN. By using such a short gate promptly after the laser pulse, the quantum yield variation with rotational level can be neglected since very little quenching has occurred. However, if the detector gate is delayed to permit rotational equilibration or is sufficiently wide to integrate the entire signal, the rotational-level-dependent quantum yields may produce significant errors in the temperature. For $\mathrm{OH}$ in a stoichiometric 7.2-Torr $\mathrm{H}_{2} / \mathrm{N}_{2} \mathrm{O}$ flame, the quantum yield has significant dependence on rotational level only in the reaction zone. ${ }^{31}$ In the burnt gases, this dependence can be safely neglected at the $\pm 50 \mathrm{~K}$ precision. However, without a short, prompt detector gate in the reaction zone, errors of $100-200 \mathrm{~K}$ may result. For NH, the rotational-level-dependent quenching can cause errors of $\sim 150 \mathrm{~K}$, and for $\mathrm{CH}$ such effects can cause systematic errors as large as $400 \mathrm{~K}$ in propane and acetylene flames. Again these problems are avoided in low pressure flames with a short, prompt detector gate. 


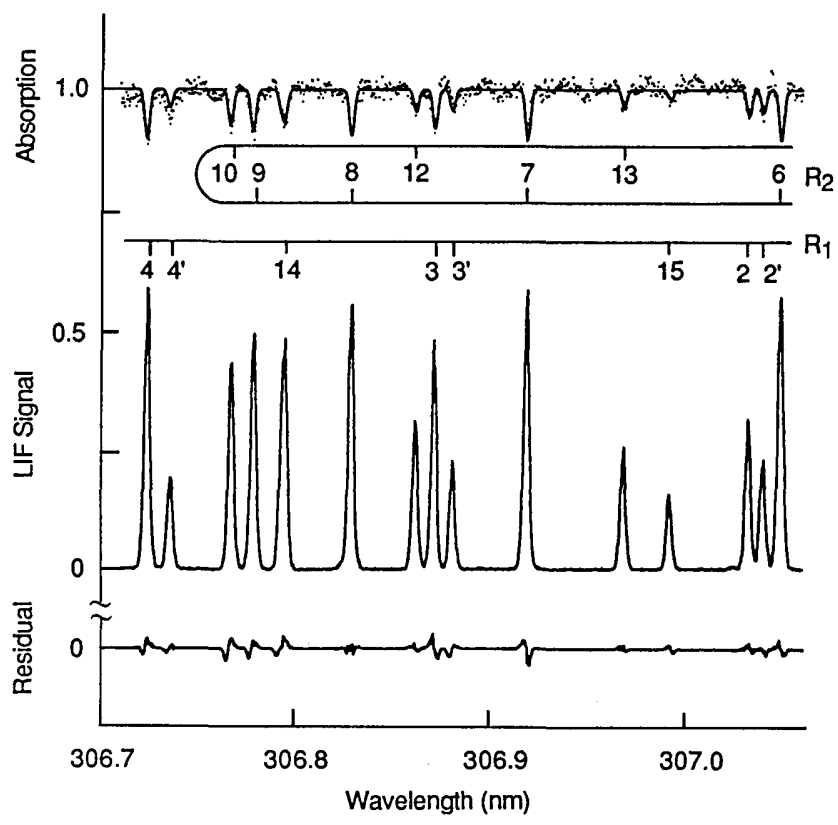

Fig. 6. $\mathrm{OH}\left(A^{2} \Sigma^{+}-X^{2} \Pi_{i}\right) \mathrm{LIF}$ spectrum (middle) and absorption spectrum (top) in the $R$-branch region in a 7.2-Torr, $\phi=1, \mathrm{H}_{2} / \mathrm{N}_{2} \mathrm{O}$ flame. The LIF spectrum gives a temperature of $2250 \mathrm{~K}$. The absorption spectrum gives a temperature of $1990 \mathrm{~K}$, which is a concentration weighted average over the flame and its cooler boundary. The bottom trace is the residual to the fit for the LIF spectrum.

\section{E. Optical Depth}

In these low pressure flames, $\mathrm{OH}$ is the only radical for which we see significant $(>1 \%)$ absorption. For $\mathrm{OH}$ in a 7.2-Torr stoichiometric $\mathrm{H}_{2} / \mathrm{N}_{2} \mathrm{O}$ flame, we see as much as $9 \%$ absorption on the strongest lines of the $R$-branch. This absorption must be considered quantitatively. The boundary between the flame and the background gas is cooler than the flame itself. The $\mathrm{OH}$ radicals in this boundary layer have more population in the lower rotational levels. Thus, there is more absorption by the low rotational levels, both of the excitation laser beam as it traverses to the uniform probed region of the burner and of the subsequent fluorescence on its way to the detector. Recall that the upper electronic state does not thermalize, so low initially excited rotational levels will radiate through transitions absorbed by low levels. With increased absorption of both the laser and the fluorescence by lower rotational levels, the apparent temperature from the excitation scan becomes too high. Both the absorption and boundary layer effects are evident in the rotational excitation scan for $\mathrm{OH}$ displayed in Fig. 6 . The spectrum is taken from the burnt gases of a 7.2Torr stoichiometric $\mathrm{H}_{2} / \mathrm{N}_{2} \mathrm{O}$ flame. The top trace shows an absorption spectrum along the line of sight through the flame and the bottom trace is the corresponding LIF excitation spectrum from the uniform flat flame. The absorption spectrum is fit to a temperature of $1990 \mathrm{~K}$, reflecting a concentration weighted average over the flame and its cooler boundary. Without correcting for absorption, the LIF spectrum is fit to a temperature of $2330 \mathrm{~K}$. The absorption correction to the LIF spectrum as described below results in a temperature of $2250 \mathrm{~K}$, corresponding to an error of $+80 \mathrm{~K}$.

The horizontal position of the burner for most of the $\mathrm{OH}$ measurements has a $5-\mathrm{cm}$ traverse of the flame by the laser beam and a detection path length of $1.5 \mathrm{~cm}$ through the flame. In these experiments, the absorption correction is made by a particularly expedient normalization of the LIF signal by the laser intensity, as monitored by a postflame photodiode which measures absorption of the laser beam over the entire $5-\mathrm{cm}$ path length. The excitation is in the $R$-branch and the prompt detector gate ensures that most of the observed fluorescence originates from the initially excited rotational level. The fluorescence is emitted and reabsorbed in all three rotational branches, which have different line strengths. Thus, we need to correct for the absorption of the laser beam in the $R$-branch over the $2.5 \mathrm{~cm}$ from the edge of the flame to the center of the flame, where we image the LIF, and we need to correct for the absorption of the fluorescence in all three branches over the shorter $1.5 \mathrm{~cm}$ out of the flame. For the path lengths in this experiment, the absorption of the laser in the $R$-branch over the longer path length $(2.5-\mathrm{cm})$ is equivalent to the absorption of the fluorescence in the $P_{-}, Q_{-}$, and $R$-branches of the shorter path. Thus, the laser absorption over the entire path through the flame provides a measure of the total absorption. For a different experimental set up with different path lengths, the proper absorption correction must be recalculated. The temperatures and radical profiles, corrected for absorption, measured at the center of the burner agree with those taken at the position closer to the edge, ensuring that the flame is sufficiently flat for a meaningful comparison.

One method that we did not explore, but deserves further study, is to use the $\mathrm{OH}(A-X)(1,0)$ band for excitation. Absorption of the excitation laser beam by the ground state radical is less, by a factor of three, because of the reduced transition probability for this band. However, excitation to $v^{\prime}=1$ introduces further complications in the detection scheme. The $(1,1)$ and $(0,0)$ bands overlap each other, so neither can be cleanly detected without collecting fluorescence from the other. The $(1,0)$ band could be used for detection; about a third of the fluorescence from $v^{\prime}=1$ is in this band. However, a further complication is that the rotational level dependence of the amount of vibrational relaxation from $v^{\prime}=1$ to $v^{\prime}=0$ vs electronic quenching varies with collision partner ${ }^{34}$ and will therefore change throughout the flame profile. In our low pressure flames where we can use a short detector gate, this would not be a severe problem.

\section{Temperature Comparisons}

Rotational temperatures of both $\mathrm{NH}$ and $\mathrm{OH}$ are measured in a 7.2-Torr $\mathrm{H}_{2} / \mathrm{N}_{2} \mathrm{O}$ stoichiometric (fuel equivalence ratio $\phi=1.0$ ) flame, and the values are plotted vs height above the burner in Fig. 7. The wavelength regions scanned are given in Table I. The 


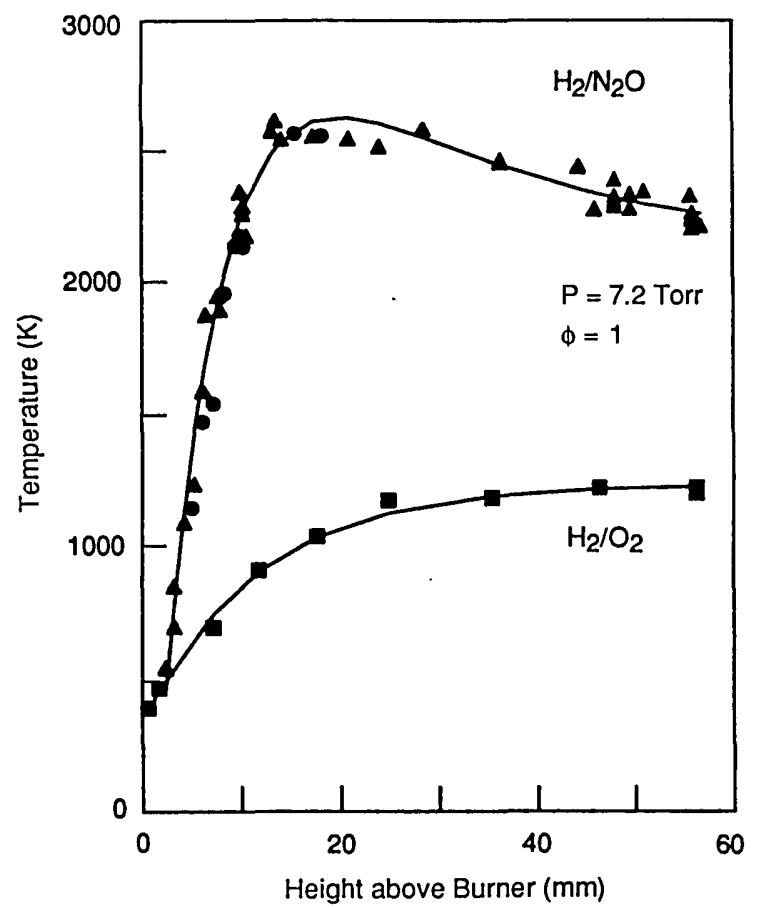

Fig. 7. Temperature profiles for a 7.2-Torr, $\phi=1, \mathrm{H}_{2} / \mathrm{N}_{2} \mathrm{O}$ flame (top) and $\mathrm{H}_{2} / \mathrm{O}_{2}$ flame (bottom). The triangles show the $\mathrm{OH}$ temperature and the circles the $\mathrm{NH}$ temperature in the $\mathrm{H}_{2} / \mathrm{N}_{2} \mathrm{O}$ flame.

The boxes show the $\mathrm{OH}$ temperature in the $\mathrm{H}_{2} / \mathrm{O}_{2}$ flame.

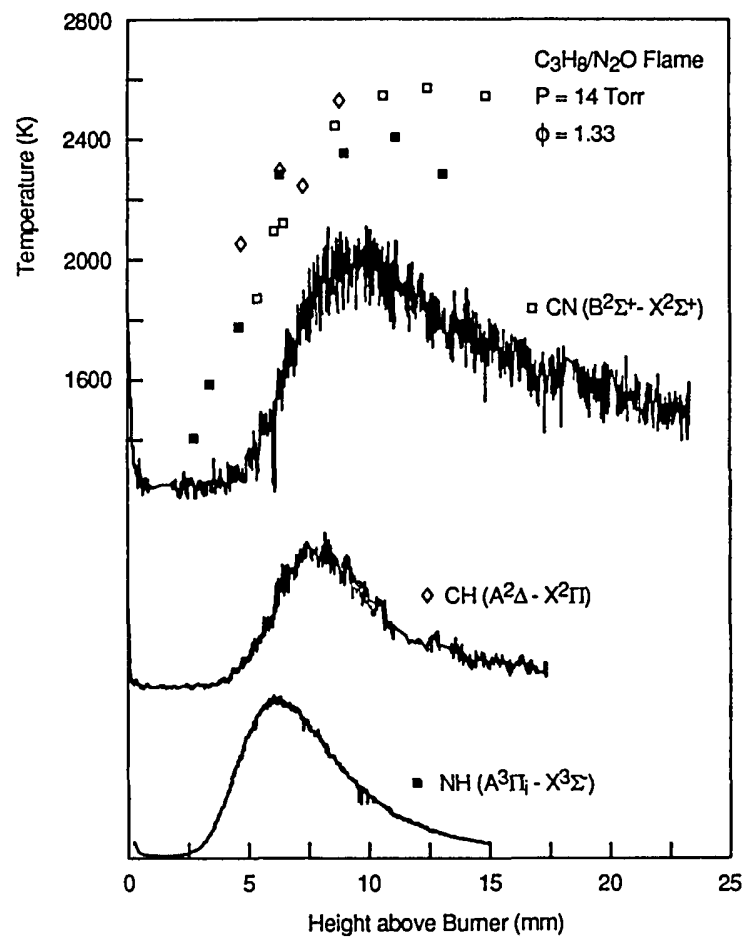

Fig. 8. Temperature and LIF signal profiles for a 14-Torr, $\phi=1.33$, $\mathrm{C}_{3} \mathrm{H}_{8} / \mathrm{N}_{2} \mathrm{O}$ flame. The signal profiles are for $\mathrm{CN}, \mathrm{CH}$, and $\mathrm{NH}$ (top to bottom). The open boxes, diamonds, and solid boxes correspond to temperatures measured using $\mathrm{CN}\left(B^{2} \Sigma^{+}-X^{2} \Sigma^{+}\right), \mathrm{CH}\left(A^{2} \Delta-X^{2} \Pi\right)$, and $\mathrm{NH}\left(A^{3} \Pi_{i}-X^{3} \Sigma^{-}\right)$rotational excitation spectra, respectively. measured $\mathrm{NH}$ and $\mathrm{OH}$ temperatures agree to $\pm 50 \mathrm{~K}$. The good agreement indicates that the method described above properly accounts for the influence of rotational-level-dependent oscillator strength and optical depth problems possible for the $\mathrm{OH}$ measurements. The temperature at the point $46 \mathrm{~mm}$ above the burner, in the burnt gases, was measured 13 times over a period of two weeks. The average temperature measured is $2320 \pm 30 \mathrm{~K}$, which is indicative of the statistical precision of the $\mathrm{OH}$ measurements.

Figure 7 also shows the temperature profile of a 7.2Torr, $\phi=1, \mathrm{H}_{2} / \mathrm{O}_{2}$ flame as measured from $\mathrm{OH}$ excitation spectra. Note that temperature measurements are possible at temperatures as low as $400 \mathrm{~K}$, at a height $1 \mathrm{~mm}$ above the burner. Despite the large heat release available for $\mathrm{H}_{2}$ and $\mathrm{O}_{2}$, this low pressure flame burns at a very low temperature. The burnt gas temperature is only $1200 \mathrm{~K}$; this difference with $T_{\text {adiabatic }}$ has been observed previously. ${ }^{35}$ By seeding $(<10 \%)$ methane into an $\mathrm{H}_{2} / \mathrm{O}_{2}$ flame, a temperature measurement using the $A-X$ system of $\mathrm{CH}$ is made; it agrees with this low OH LIF flame temperature.

In a second series of experiments, the $\mathrm{CH}, \mathrm{NH}$, and $\mathrm{CN}$ radical are all used to measure the temperature in the same 15-Torr, rich $(\phi=1.33) \mathrm{C}_{3} \mathrm{H}_{8} / \mathrm{N}_{2} \mathrm{O}$ flame. The measured temperature and radical LIF profiles for each species are given as a function of height above the burner in Fig. 8. The intense $\mathrm{CN}$ fluorescence overwhelms that of the $\mathrm{CH} B-X$ system which is in the same spectral region, so only the $\mathrm{CH} A-X$ system can be used in this flame. The relevant scan parameters are given in Table I. Most of the measurements with CH $A-X$ agree within $100 \mathrm{~K}$ with those using $\mathrm{NH} A-X$. Thus, we have observed agreement for temperature measurements from $\mathrm{NH}, \mathrm{CH}(A-X)$, and $\mathrm{OH}$ excitation scans. However, the measurements for $\mathrm{CN}$ in the burnt gases are consistently $200 \mathrm{~K}$ high. One reason may be rotational-level-dependent quantum yields. There is no collisional quenching data for $\mathrm{CN}$ in this flame and the radiative lifetime is too short $(65 \mathrm{~ns})^{36}$ for the quantum yield to be neglected with our 10-ns detection gate. This discrepancy deserves further study.

In another comparison, the temperatures are determined in a 6.8-Torr, $\phi=1, \mathrm{C}_{3} \mathrm{H}_{8} / \mathrm{O}_{2}$ flame using both the $A-X$ and $B-X$ systems of $C H$. The regions scanned are given in Table I. The temperature and $\mathrm{CH}$ radical concentration profiles in this flame are presented in Fig. 9. $\mathrm{CH}$ is present only in the reaction zone. For reasons we do not understand, temperatures measured using the $B-X$ excitation spectra are systematically $150-200 \mathrm{~K}$ lower than those obtained with the $\mathrm{CH} A-X$ system. Note that $\mathrm{CH}\left(B^{2} \Sigma^{-}\right)$predissociates ${ }^{29(c)}$ rapidly for $N \geq 15$. If rotational energy transfer from the higher levels excited in the rotational excitation spectrum can rapidly transfer $>10 \%$ of their population to these predissociating levels, such a discrepancy could be explained. However, experiments with varying detector gate delays, as described above for $\mathrm{OH}$, will be necessary to test this hypothesis. 


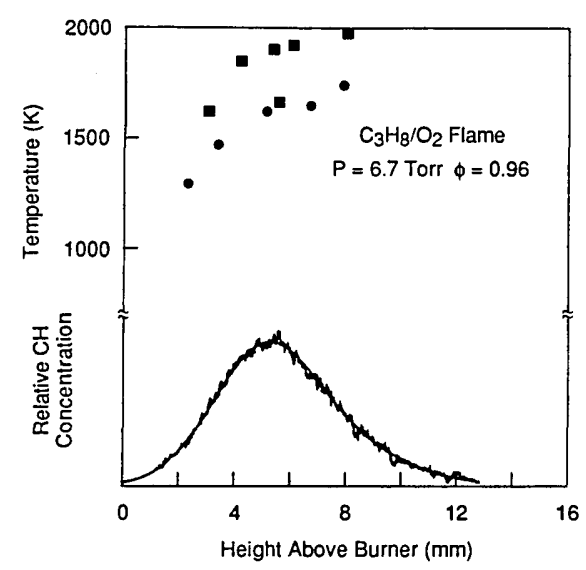

Fig. 9. Temperature and $\mathrm{CH}$ profiles for a 6.7-Torr, $\phi=0.96, \mathrm{C}_{3} \mathrm{H}_{8} /$ $\mathrm{O}_{2}$ flame. The boxes and circles show temperatures determined from $\mathrm{CH}\left(A^{2} \Delta-X^{2} \Pi\right)$ and $\mathrm{CH}\left(B^{2} \Sigma^{-}-X^{2} \Pi\right)$ rotational excitation spectra, respectively. The bottom curve is the relative $\mathrm{CH}$ radical concentration. The line through the $\mathrm{CH}$ profile is synthesized from the parametrization data in Ref. 5.

\section{Summary}

We have assessed the systematic temperature measurement errors from the detector spectral bias, temporal gate width, and rotational-level-dependent oscillator strength for the hydride radicals $\mathrm{OH}, \mathrm{NH}$, and $\mathrm{CH}$. For low pressure flames where the fluorescence lifetime is long compared to the excitation pulse length and detector gate, we have agreement for the temperatures measured from the excitation spectra of the three radicals to $\sim 100 \mathrm{~K}$. Even with the careful measurement methods described above for these laminar laboratory low pressure flames, we do not obtain this reasonable agreement for measurements using the $B$ $X$ system for $\mathrm{CH}$ or the $B-X$ system of CN. This points to additional rotational-level-dependent effects which might influence LIF measurements of temperature with these radicals.

The participation of Michael Wise was made possible by a grant from the National Science Foundation program for Research Experiences for Undergraduates. The work on $\mathrm{OH}$ was supported by the Division of Basic Energy Sciences of the Department of Energy. That on NH was supported by the Thermal Systems and Engineering program of the National Science Foundation. The measurements on $\mathrm{CH}$ and $\mathrm{CN}$ were supported by the Aero Propulsion Laboratory of the Air Force Wright Aeronautical Laboratories. Katharine Kohse-Höinghaus is on leave from the Institut für Physikalische Chemie der Verbrennung of DFVLR.

\section{References}

1. D. R. Crosley and G. P. Smith, "Laser-Induced Fluorescence Spectroscopy for Combustion Diagnostics," Opt. Engr. 22, 545553 (1983); J. H. Bechtel, C. J. Dasch, and R. Teets, "Combustion Research with Lasers" in Laser Applications, R. K. Erf and J. F. Ready, Eds. (Academic, New York, 1983); R. P. Lucht, "Applications of Laser-Induced Fluorescence Spectroscopy for
Combustion and Plasma Diagnostics" in Laser Spectroscopy and Its Applications, L. J. Radziemski, R. Solarz, and J. A. Paisner, Eds. (Marcel Dekker, New York, 1986); D. R. Crosley, "Laser-Induced Fluorescence Measurement of Combustion Chemistry Intermediates," High Temp. Mat. Proc. 7, 41-54 (1986); A. C. Eckbreth, Laser Diagnostics for Combustion Temperature and Species (Abacus, Cambridge, MA 1987).

2. K. Kohse-Höinghaus, P. Koczar, and T. Just, "Absolute Concentration Measurements of $\mathrm{OH}$ in Low Pressure Hydrogen-Oxygen, Methane-Oxygen and Acetylene-Oxygen Flames," in Twenty-First Symposium (International) on Combustion (The Combustion Institute, Pittsburgh, 1988), p. 1719-1727.

3. A. G. Gaydon and H. G. Wolfhard, Flames, Their Structure, Radiation and Temperature, Fourth Edition (Chapman \& Hall, London, 1979).

4. S. S. Penner, C. P. Wang, and M. Y. Bahadori, "Laser Diagnostics Applied to Combustion Studies," in Twentieth Symposium (International) on Combustion (The Combustion Institute, Pittsburgh, 1985), p. 1149-1176.

5. K. J. Rensberger, M. J. Dyer, and R. A. Copeland, "TimeResolved $\mathrm{CH}\left(A^{2} \Delta\right.$ and $\left.B^{2} \Sigma^{-}\right)$Laser-Induced Fluorescence in Low Pressure Hydrocarbon Flames," Appl. Opt. 27, 3679-3689 (1988).

6. A. M. Wodtke, L. Huwel, H. Schlüter, H. Voges, G. Meijer, and P. Andresen, "Predissociation of $\mathrm{O}_{2}$ in the $B$ State," J. Chem. Phys. 89, 1929-1935 (1988).

7. G. Laufer and R. L. McKenzie, "Temperature Measurements in Hypersonic Air Flows using Laser-Induced $\mathrm{O}_{2}$-Fluorescence," AIAA/NASA/AFWAL Conference on Sensors and Measurements Techniques for Aeronautical Applications, Atlanta, September 1988.

8. P. Andresen, A. Bath, S. Gröger, H. W. Lülf, G. Meijer, and J. J. ter Meulen, "Laser-Induced Fluorescence with Tunable Excimer Lasers as a Possible Method for Instantaneous Temperature Field Measurements at High Pressures: Checks with an Atmospheric Flame," Appl. Opt. 27, 365-378 (1988).

9. A. C. Eckbreth, "Recent Advances in Laser Diagnostics for Temperature and Species Concentration in Combustion," in Eighteenth Symposium (International) on Combustion (The Combustion Institute, Pittsburgh, 1981), p. 1471-1488.

10. W. R. Anderson, L. J. Decker, and A. J. Kotlar, "Temperature Profile of a Stoichiometric $\mathrm{CH}_{4} / \mathrm{N}_{2} \mathrm{O}$ Flame from Laser Excited Fluorescence Measurements on $\mathrm{OH}$," Combust. Flame 48, 163177 (1982).

11. G. H. Dieke and H. M. Crosswhite, "The Ultraviolet Bands of OH," J. Quant. Spectrosc. Radiat. Transfer 2, 97-199 (1962).

12. C. R. Brazier, R. S. Ram, and P.F. Bernath, "Fourier Transform Spectroscopy of the $A^{3} \Pi-X^{3} \Sigma^{-}$Transition of NH," J. Mol. Spectrosc. 120, 381-402 (1986).

13. C. E. Moore and H. P. Broida, "CH in the Solar Spectrum," J. Res. Natl. Bur. Stand. 63A, 19-53 (1959).

14. J. M. Brown, J. T. Hougen, K. P. Huber, J. W. C. Johns, I. Kopp, H. Lefebvre-Brion, A. J. Merer, D. A. Ramsay, J. Kostas, and R. N. Zare, "The Labeling of Parity Doublet Levels in Linear Molecules," J. Mol. Spectrosc. 55, 500-503 (1975).

15. M. B. Colket,"Spectroscopic Absorption Model for $\mathrm{CN}\left(X^{2} \Sigma \rightarrow B^{2} \Sigma\right)$ : Comparison of Experiments and Theory," J. Quant. Spectrosc. Radiat. Transfer 31, 7-13 (1984).

16. G. H. Mount, J. L. Linsky, and R. A. Shine, "One- and MultiComponent Models of the Upper Photosphere Based on Molecular Spectra," Sol. Phys. 32, 13-30 (1973).

17. R. N. Zare, A. L. Schmeltekopf, W. J. Harrop, and D. L. Albritton, "A Direct Approach for the Reduction of Diatomic Spectra to Molecular Constants for the Construction of RKR Potentials," J. Mol. Spectrosc. 46, 37-66 (1973).

18. B. M. Krupp, "A New Analysis of the $A^{2} \Delta-X^{2} \Pi$ System of $\mathrm{CH}$," Astrophys. J. 189, 389-397 (1974). 
19. I. Botterud, A. Lofthus, and L. Veseth, "Term Values and Molecular Parameters for $\mathrm{CH}$ and $\mathrm{CH}^{+}$," Phys. Scr. 8, 218-224 (1973).

20. K. P. Huber and G. Herzberg, Constants of Diatomic Molecules (Van Nostrand/Reinhold, New York, 1979).

21. D. R. Crosley and R. K. Lengel, "Relative Transition Probabilities and the Electronic Transition Moment in the $A-X$ System of OH," J. Quant. Spectrosc. Radiat. Transfer 15, 579-591 (1975).

22. I. L. Chidsey and D. R. Crosley, "Calculated Rotational Transition Probabilities for the A-X System of $\mathrm{OH}$," J. Quant. Spectrosc. Radiat. Transfer 23, 187-199 (1980).

23. D. R. Crosley, "Semiquantitative Laser-Induced Fluorescence in Flames," Combust. Flame, 00, 000 in press, 1989.

24. G. P. Smith and D. R. Crosley, "Quantitative Laser-Induced Fluorescence in OH: Transition Probabilities and the Influence of Energy Transfer," in Eighteenth Symposium (International) on Combustion (The Combustion Institute, Pittsburgh, 1981), p. 1511-1520; D. R. Crosley and G. P. Smith, "Rotational Energy Transfer and LIF Temperature Measurements," Combust. Flame 44, 27-34 (1982).

25. C. Chan and J. W. Daily, "Laser Excitation Dynamics of $\mathrm{OH}$ in Flames," Appl. Opt. 19, 1357-1367 (1980); R. P. Lucht, D. W. Sweeney, and N. M. Laurendeau, "Time-Resolved Fluorescence Investigation of Rotational Transfer in $A^{2} \Sigma^{+}(v=0) \mathrm{OH}$," Appl. Opt. 25, 4086-4095 (1986).

26. N. L. Garland and D. R. Crosley, "Energy Transfer Processes in CH $A^{2} \triangle$ and $B^{2} \Sigma^{-}$in an Atmospheric Pressure Flame," Appl. Opt. 24, 4229-4237 (1985).

27. R. J. Cattolica, D. Stepowski, D. Puechberty, and M. Cottereau, "Laser-Induced Fluorescence of the $\mathrm{CH}$ Molecule in a Low Pressure Flame," J. Quant. Spectrosc. Transfer 32, 363-370 (1984).

28. R. G. Joklik and J. W. Daily, "LIF Study of $\mathrm{CH} A^{2} \Delta$ Collision Dynamics in a Low Pressure Oxy-Acetylene Flame," Combust. Flame 69, 211-219 (1987).

29. (a) OH: K. R. German, "Direct Measurements of the Radiative Lifetimes of the $A^{2} \Sigma^{+}\left(v^{\prime}=0\right)$ States of $\mathrm{OH}$ and OD," J. Chem. Phys. 62, 2584-2587 (1975); J. Brzozowski, P. Erman, and M. Lyyra, "Precision Estimates of the Predissociation Rates of the OH $A^{2} \Sigma^{+}$State $(v \leq 2)$," Phys. Scr. 17, 507-511 (1978); I. S. McDermid and J. B. Laudenslager, "Radiative Lifetimes and Quenching Rate Coefficients for Directly Excited Rotational Levels of $\mathrm{OH}\left(A^{2} \Sigma^{+}, v^{\prime}=0\right)$," J. Chem. Phys. 76, 1824-1831 (1982).

29. (b) NH: W. H. Smith, J. Brzozowski, and P. Erman, "Lifetime
Studies of the NH Molecule: New Predissociations, the Dissociative Energy, and Interstellar Diatomic Recombination," J. Chem. Phys. 64, 4628-4633 (1976).

29. (c) CH: J. Brzozowski, P. Bunker, N. Elander, and P. Erman, "Predissociation Effects in the $A, B$, and $C$ States of $\mathrm{CH}$ and the Interstellar Formation Rate of $\mathrm{CH}$ via Inverse Predissociation," Astrophys. J. 207, 414-424 (1976).

30. (a) OH: R. A. Copeland, M. J. Dyer, and D. R. Crosley, "Rotational-Level-Dependent Quenching of $A^{2} \Sigma^{+} \mathrm{OH}$ and OD," J. Chem. Phys. 82, 4022-4032 (1985).

30. (b) NH: N. L. Garland and D. R. Crosley, "Rotational-LevelDependent Quenching of the $A^{3} \Pi_{i}, v^{\prime}=0$ State of NH," J. Chem. Phys., 90, 3566-3573 (1989).

31. K. Kohse-Höinghaus, J. B. Jeffries, R. A. Copeland, G. P. Smith, and D. R. Crosley, "The Quantitative LIF Determination of $\mathrm{OH}$ Concentrations in Low Pressure Flames," in Twenty-Second Symposium (International) on Combustion (The Combustion Institute, Seattle, 1988), pp. 00-00 in press; J. B. Jeffries, K. Kohse-Höinghaus, G. P. Smith, R. A. Copeland, and D. R. Crosley, "Rotational-Level-Dependent Quenching of $\mathrm{OH}\left(A^{2} \Sigma^{+}\right)$at Flame Temperatures," Chem. Phys. Lett., 152, 160-166 1988.

32. K. J. Rensberger, R. A. Copeland, M. L. Wise, and D. R. Crosley, "NH and $\mathrm{CH}$ Laser-Induced Fluorescence in Low Pressure Flames: Quantum Yields from Time-Resolved Measurements," in Twenty-Second Symposium (International) on Combustion (The Combustion Institute, Seattle, 1988) pp. 000000 , in press.

33. R. A. Copeland, M. L. Wise, K. J. Rensberger, and D. R. Crosley, "Time-Resolved Laser-Induced Fluorescence of the NH Radical in Low Pressure $\mathrm{N}_{2}$ O Flames," Appl. Opt. 28, 000-000 (1989), in press, 1 Aug.

34. R. K. Lengel and D. R. Crosley, "Energy Transfer in $A^{2} \Sigma^{+} \mathrm{OH}$. II. Vibrational," J. Chem. Phys. 68, 5309-0000 (1978); G. P. Smith and D. R. Crosley, "Vibrational Energy Transfer in $A^{2} \Sigma^{+}$ OH in Flames," Appl. Opt. 22, 1428-0000 (1983); R. A. Copeland, M. L. Wise, and D. R. Crosley, "Vibrational Energy Transfer and Quenching of $\mathrm{OH}\left(A^{2} \Sigma^{+}, v^{\prime}=1\right)$," J. Phys. Chem., 92, 5710-5715, 1988.

35. K. H. Eberius, K. Hoyermann, and H. G. Wagner, "Experimental and Mathematical Study of a Hydrogen-Oxygen Flame," in Thirteenth Symposium (International) on Combustion (The Combustion Institute, Pittsburgh, PA 1971), pp. 713-721.

36. N. Duric, P. Erman, and M. Larsson, "The Influence of Collisional Transfers and Perturbations on Measured A and B State Lifetimes in CN," Phys. Scr. 18, 39-46 (1978). 